\title{
Formulation of Extended Release
}

\author{
Theophylline Tablets - \\ experimental, modelling and \\ bio-equivalence studies
}

by

Kamal Kumara Gamini Mahendranath Parakrama

Bandara Herath

Ph. D. 


\section{Formulation of Extended Release Theophylline Tablets - experimental, modelling and bio-equivalence studies}

by

Kamal Kumara Gamini Mahendranath Parakrama Bandara Herath

Thesis submitted to the University of Sri Jayawardenepura, for the award of the Degree of Doctor of Philosophy in Chemistry (Pharmaceutics) on 30 ${ }^{\text {th }}$ July 2004. 
The work described in this thesis was carried out by me under the supervision of Prof. A. M. Abeysekera (B.Sc., Ph.D.) Department of Chemistry, University of Sri Jayawardenepura

And

Dr. Anil K. E. Goonethileke (MBBS, MD, MRCP) Department of Pharmacology, University of Sri Jayawardeneapura)

And a report on this thesis has not been submitted in whole or in part to any other University for another degree / Diploma.

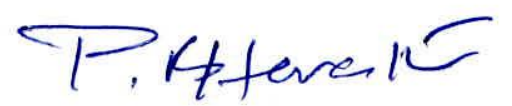

K.K.G.M.P.B. Herath. BA (Chemistry - major, Biology - minor) Wartburg College, USA, MSc. (Organic Chemistry) Iowa state University, Ames, IA, USA. 
We certify that the above statement made by the candidate is true and that this thesis is suitable for submission to the University for the purpose of evaluation.

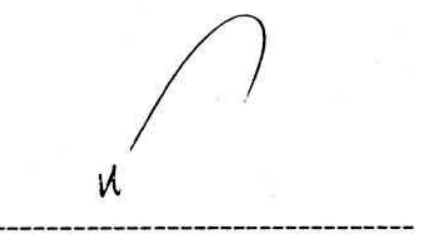

Dr. Anil K.E. Goonethileke,

Depártment of Pharmacology,

Faculty of Medical Sciences,

University of Sri Jayawardenepura

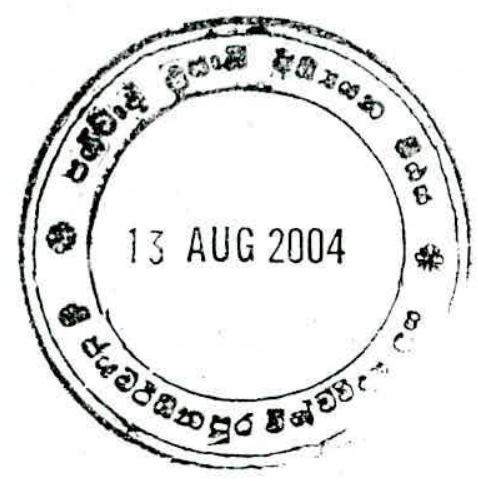

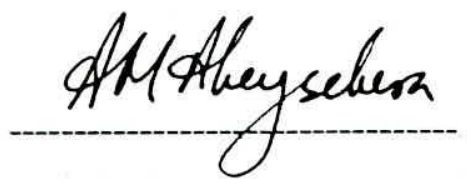

Prof. A. M. Abeysekera,

Department of Chemistry,

Faculty of Applied Sciences,

University of Sri Jayawardenepura)

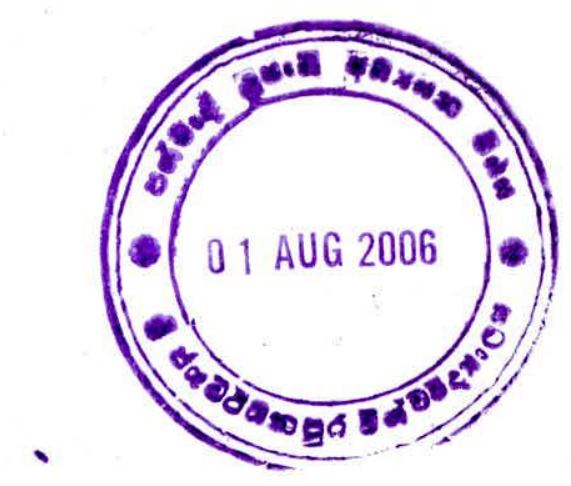




\section{Table of contents}

Contents

Page numbers

Title page

Table of Contents

$i-v i$

List of Tables and Figures

$$
v i i-x i i
$$

Acknowledgement

xiii-xiv

Abbreviations

$x v$

Abstract

$x v i-x v i i i$

1. Introduction

1.1 Theophylline 3

1.2 Use and pharmacological aspects of theophylline 3

1.3 Pharmacokinetics to model in-vivo requirements 7

1.4 Biological factors considered in selecting theophylline as an oral extended release dosage

1.5 Release rate controlling techniques used

in oral extended-release dosage forms

1.6 Theoretical models of drug release

1. 7 Chemical stability of theophylline and formulation methodology 
1.8 Compounds of theophylline employed in formulations

1.9 Clinical studies - bioavailability and bioequivalence

1.10 Objectives of the thesis

\subsection{Materials and Methods}

$\begin{array}{lll}2.1 & \text { Materials } & 32\end{array}$

$\begin{array}{lll}2.2 & \text { Apparatus } & 33\end{array}$

2.3 Analysis of Theophylline Anhydrous raw materials 34

2.4 Preparation of the blends 36

$\begin{array}{lll}2.5 & \text { Blend property measurements } & 36\end{array}$

$\begin{array}{ll}2.6 & \text { Compression of the tablets } \\ \end{array}$

$\begin{array}{lll}2.7 & \text { In-process control } & 39\end{array}$

2.8 Quality Control Protocol For Theophylline Tablets 40

$\begin{array}{lll}2.9 & \text { Stability studies } & 40\end{array}$

$\begin{array}{lll}2.10 & \text { Packaging and storage } & 42\end{array}$

2.11 Measurement of eroding rate of tablets 43

2.12 Bio-Equivalence Study Protocol 43 


\subsection{Results}

Table 1 Intrinsic dissolution of theophylline raw material

Table 2 Particle size distribution of final blend for Theophylline extended release

Table 3 Moisture of the final blend for Theophylline extended release tablets

Table 4 Individual tablet weights and dissolution of 3 separate lots with Formula no. FD00M01 in Table 22

Figure 6 Running chart of weight difference of tablets with time graph

Table 5 Diameter of the Tablets in 3 different lots

Table 6 Thickness of the Tablets

Table 7 Hardness of Tablets from ' 3 lots of $125 \mathrm{mg}$ strength

Table 8 Hardness of Tablets from 3 lots of $300 \mathrm{mg}$ strength 52

Table 9 Friability of Tablets from 3 lots of $125 \mathrm{mg}$ strength 52

Table 10 Friability of Tablets from 3 lots of $300 \mathrm{mg}$ strength 52

Table 11 Drug release results of theophylline tablets ER 300mg- 53

Actual results are given below at time points for 3 lots.

Table 12 Assay of Theophylline tablets $125 \mathrm{mg}$

Table 13 Accelerated stability test results of theophylline ER $125 \mathrm{mg}$ 55 tablets stored at $60^{\circ} \mathrm{C}$ 
Table 14 Measurement of eroding rate of Tablets

Table 15 Dissolution rate of 4 modified release tablets

available in the Sri Lankan market.

Table 16 Dissolution profiles of the Nuline 250 SR tablets and

SPMC-Theophylline extended release tablets, two of $125 \mathrm{mg}$

(Total $250 \mathrm{mg}$ strength), in $\mathrm{pH} 2.0$ and 7.4 dissolution media

Table 17 Demographic data of subjects participated for the

bio equivalence study regarding age, weight, height and history of asthma

Table 18 Demographic data regarding the smoking, allergy, and concurrent medication the subjects participated in the bio-equivalence study

Table 19 Theophylline concentration in blood serum

\subsection{Discussion}

4.0 Introduction 60

4.1 Development of theophylline extended release formulations 60 
4.1.3 Summery of extended release formulation development

4.2 Modelling Bio-erodible Tablet as a Dissolution and Diffusion Controlled System

4.2.1 Mathematical modelling

4.2.2 Selection of the form of diffusion coefficient for spherical tablet using experimental data

4.2.3 Derivation of equations for a cylindrical tablet

4.2.4 A general form of dissolution formula to be used with both spherical and cylindrical tablets

Generalizing the dissolution formula

4.2.5 Summery of Modelling Bio-erodible Tablet

4.3 Bioequivalence Study

4.3.0 Introduction

4.3.1 Purpose of the Study

4.3.2 In-vitro and in-vivo study of commercially available products

4.3.3 Drug administration and the blood sample collection

4.3.4 Results of the bioequivalence study 
5.0 Quality Control Protocol

5.0 Introduction

5.1 Quality Control Protocol of Theophylline extended release tablèts

5.2 Summery of Quality Control Protocol

Conclusion

List of References

Appendices

Appendix

I

1-06

Appendix

II

1-24

Appendix

III

1-17

Appendix

IV

$1-20$ 
$\begin{array}{lll}\text { Fig. } 1 & \text { Serum drug level versus time } & 10\end{array}$

$\begin{array}{lll}\text { Fig. } 2 \text { Dissolution controlled drug delivery system in beads } & 12\end{array}$

$\begin{array}{lll}\text { Fig. } 3 & \text { Diffusion controlled drug delivery system } & 13\end{array}$

$\begin{array}{lll}\text { Fig. } 4 & \text { Bio-erodable matrix system } & 14\end{array}$

$\begin{array}{lll}\text { Fig. } 5 & \text { Osmotic Control Drug delivery Systems } & 16\end{array}$

Table 1 Intrinsic dissolution of theophylline raw material 46

Table 2 Particle size distribution of final blend for Theophylline 48

extended release

Table 3 Moisture of the final blend for Theophylline extended 48

release tablets

Table 4 Individual tablet weights and dissolution ratio with formula

No. FD00M01 (given in Table 22) of 3 separate lots

Fig. 6 Running chart of weight difference of tablets with time

graph

Table 5 Diameter of the Tablets in 3 different lots

Table 6 Thickness of the Tablets

Table 7 Hardness of Tablets from 3 lots of $125 \mathrm{mg}$ strength

Table $8 \quad$ Hardness of Tablets from 3 lots of $300 \mathrm{mg}$ strength 
Table 9 Friability of Tablets from 3 lots of $125 \mathrm{mg}$ strength

Table $10 \quad$ Friability of Tablets from 3 lots of $300 \mathrm{mg}$ strength 52

Table 11 Drug release results of theophylline tablets ER 300mg- $\quad 53$

Actual results are given below at time points for 3 lots.

Table 12 Assay of Theophylline tablets $125 \mathrm{mg} \quad 54$

Table 13 Accelerated stability test results of theophylline ER $125 \mathrm{mg} \quad 55$

tablets stored at $60^{\circ} \mathrm{C}$

Table 14 Measurement of eroding rate of Tablets 55

Table 15 Dissolution rate of 4 modified release tablets and a 56

conventional tablet available in the Sri Lankan market.

The Test method used was USP dissolution apparatus 2,

$\mathrm{pH} 4.5$ phosphate buffer at $37^{\circ} \mathrm{C}$.

Table 16 Dissolution profiles of the Nuline 250 SR tablets and

SPMC-Theophylline 2 of $125 \mathrm{mg}$ (Total of $250 \mathrm{mg}$ strength)

with $\mathrm{pH} 2.0$ and 7.4 of the dissolution media over 8 hour.

Table 17 Demographic data of subjects participated for the

bio equivalence study regarding age, weight, height and

history of asthma

Table 18 Demographic data regarding the smoking, allergy,

and concurrent medication the subjects participated

in the bio-equivalence study

Table 19 Theophylline concentration in blood serum 
Fig. 7 Eudragit ${ }^{\circledR}$ RSPO ; (I) ammonio methacrylate copolymer

Table 20 Chemical and Physical Properties of methacrylate ester copolymers

Table 21 Chemical and Physical Properties of methacrylic acid

Copolymers

Fig. 8 Dissolution profiles of methacrylic acid copolymers

Fig. 9 DQP.M ; (II) Diaryl quaternaryammonium phosphinic acid metal Complex

Fig. 10 Receptor DQP.M; (II) binds with electron rich 2 -napthoxyacitate

Table 22 The formulations with varied amount of resin per

Theophylline Extended Release tablets and their

drug release profile of formulations

Table 23 The formulations with varied amount of resin per tablet 78

Table 24 Two formulations of theophylline tablets where one has 79 Amino Methacrylate copolymer (Eudragit ${ }^{\circledR}$ RSPO) and the other has Amino Methacrylic acid copolymer (Eudragit $\circledast$ S-100) as the retardant

Fig. no. 12 Effect of $\mathrm{pH}$ on drug release of theophylline extended release 80 tablets with Eudragit@ RSPO without filler excipients

Fig. no. 13 Effect of $\mathrm{pH}$ on Drug Release of Theophylline Extended 81 Release Tablets with Eudragit S - 100 polymer and with out filler Excipient

Fig. no. 14 Intrinsic dissolution of 4 raw material consignments of 
3 manufacturers

Table 25 Effect of $\mathrm{pH}$ on Drug Release of Theophylline Extended

Release Tablets with same formula but with different filler

\section{Excipient}

Fig. 15 Variation of Dc with the percentage of retarding agent

for different $\mathrm{C}$ values for the relation given by equation (2)

Fig. 16 Variation of Dc with the percentage of retarding agent

for different $\mathrm{C}$ values for the relation given by equation (3)

Table 26 Dr for different times at different $\mathrm{X}$ values

Fig. 17 Predicted dissolution ratios for different retarding agent

value compared with observations for equation (6) using

different 'c' and ' $\alpha$ ' coefficients

Fig. 18 Predicted dissolution ratios for different retarding agent

97

value compared with observations for equation (6) using

common ' $c$ ' and ' $\alpha$ ' coefficients.

Fig. 19 Predicted dissolution ratios for different retarding agent

value compared with observations for equation (7) for

different ' $c$ ' and ' $\alpha$ ' parameters

Fig. 20 Predicted dissolution ratios for different retarding agent

value compared with observations for equation (7) for

common ' $\mathrm{C}$ ' $=0.3703$ and ' $\alpha$ ' $=0.50868$ parameters

Fig. 21 The relation of tablet radius to the tablet height 
Table 27 Dissolution ratio for the experiment FD02E02

Fig. 22 The best fit function from the cylindrical formula

compared with the experimental data for the experiment

No. FD02E02

Fig. 23 The description of the experiment FD02E02 of cylindrical

tablet using the spherical tablet formula using the

'equivalent radius' concept

Table 28 Dissolution ratio for the experiments used in generalization

106

Fig. 24 Comparison of the FD01K07 experimental data with

estimation from the optimized formula for the cylindrical

tablet given in equation (20)

Fig. 25 Comparison of the FD01K07 experimental data with

estimation from the optimized formula for the spherical

tablet given in equation (21)

Fig. 26 Comparison of the GD02E02 experimental data with

estimation from the optimized formula for the cylindrical

tablet given in equation (22)

Fig. 27 Comparison of the GD02E02 experimental data with

estimation from the optimized formula for the spherical

tablet given in equation (23)

Table 29 Optimized parameters for the two experiments

corresponding to two formulae

Fig. 28 Comparison of observations with generalized equation

Predictions

Fig. no.29 Comparison of predictions against observations for GB

class of materials expressed by the general equation (25) 
Table 30 Comparison of retail prices of various brands of imported theophylline SR with the Proposed prices of SPMCTheophylline ER Tablets as at June 30. 2003

Fig. No. 30 Dissolution profiles of 4 controlled release commercially available 117 theophylline preparations

Table 31 The Physical appearance and market information of the products 120 discussed above are tabulated in this table for Quibron TSR, Unicontin, Neulin SR and Broncodil-XL (200).

Table 32 Dissolution profiles of the Neulin 250 SR tablets and

SPMC-Theophylline 2 of $125 \mathrm{mg}$ (Total of $250 \mathrm{mg}$ strength)

with varying $\mathrm{pH}$ of the dissolution media over 6 hours

Fig. $30 \quad$ Concentration averages of 20 volunteers of thephylline in serum

with test SPMC [ T ] tab. and standard 3M (Neulin,Australia) [N]

tab (tablets) for 24 hours.

Table 33 Comparision study of weight variation of Theophylline

ER 300mg tablets with USP

Fig. 31 Variation of the theophylline concentration in serum with

time for test (SPMC) and Standard (Neuline) for

subject 1 to 20 .

Annex IV 1-10 


\section{ACKNOWLEDGEMENT}

Most of the research work of this $\mathrm{PhD}$ thesis was carried out at the State Pharmaceuticals Manufacturing Corporation (SPMC) of Sri Lanka, Ratmalana.

I wish to express my sincere gratitude to:

Dr. Anil Goonethileke, Department of Pharmacology, University of Sri Jayawardenapura, my Guru, who taught me to set standards in the field, for all his support and for never losing faith in my ability to complete this thesis. I am also grateful for his ability to turn my pessimism into moment of optimism.

Prof. A M Abeysekera, Dean, Faculty of Applied Sciences., University of Sri Jaywardenapura for precise guidance and valuable comments on manuscript. He was an inspiration to me through out the work.

Former Chairmen of SPMC Prof. Colvin Gunaratna, Mr. K A T B Jayawardena, Dr. Athula Kahandaliyanage, Mr. N Kiriella, Mr. K M S B Rekogama, and present Chairman Mr. G Y A Ravindra Jayananda, along with the respective Board of Directors for encouraging me to do research and allocating funds.

I would like to thank all Senior Managers of SPMC Mr. G. Karunapala, Mr. W. Pathirana, Mr. A.Kuruppu, Mr. S. Hewage, Mr. A. Gunarathna, and Mr. Brian Cooray, and the senior managers of the State Pharmaceuticals Corporation Mr. H.K. Sirisena, Mr. M. Kruppu, Ms Surangani and all the other SPMC Assistant Managers and Executives for their encouragement, for helpful discussions and support throughout the work.

Mr. Ajith Munisinghe, Ms. Hemanthi Rathnayaka, Mr. T A Y Wishvakeerthi, Mr. A P Sumith for all the support work in the Formulation Development Lab.

Dr. T.M.J. Munasinghe (MRI) for valuable discussions and "all ways ready to help" attitude. Dr. Kamal Gunatunage, University of Sri Jayawardanapura, for convincing patients to give blood samples, and collecting them. Dr. Preethi Zoysa, University of Colombo, 
giving valuable advice in theophylline blood level analysis. My thanks are also to all the bioequivalence study working group Dr. W.D.P.L. Wasalathanthri, Dr. N.H.Dharmatilake, and Dr. W.S.D. Chandrasiri for looking after the clinical side of the patients and having never failing in enthusiasm. I thank the entire crew in the "Health watch" for helping me in the Clinical Studies in various ways and specially Ms. Samantha and Ms. Tishari for collecting blood samples, doing liver function and other tests.

Professor D.A. Thanthirigoda, University of Sri Jayawardanapura, is also appreciated for the valuable discussions in the process of developing the mathematical model and the interest in my work.

I wish to thank all the State Pharmaceutical Manufacturing Corporation staff including the Quality Control staff for repeating analytical work, Production staff for scale-up trials and commercial scale work, Maintenance staff for maintaining the machinery and for new fabrications done, which helped my work, Planning and Procurement staff of the for supplying raw materials.

My gratitude goes to the entire volunteer group who participated in the Bio-equivalence study, for been patient, and trusting the newly developed product and my commitment to the project.

The State Pharmaceuticals Manufacturing Corporation for Financial support for the project, Health Watch (Pvt.) Ltd. Colombo, Sri Lanka, Hemas Pharmaceuticals (Pte) Ltd, Colombo 1, Sri Lanka, and Abbot diagnostics, Karachchi, Pakistan for Providing instruments and Chemicals

My wife Suleka, son Aroshana, brothers Prof. Sirkantha, Bandara, Kerthi Herath, and their wifes Mrs. Sujatha Herath, Mrs. Cecil Herath my father-in-law Mr. Elmo de Silva and mother-in-law Mrs. Neomi De Silva for their support, tolerating my always busy schedules, and all helping me in many ways, to survive through the long years of study.

Last but not least that the driving force for the research study was from my beloved parents late Appachi Mr. K. B. Herath and late Amma Mrs. Malini Herath, thank you for always encouraging me to study. 


\section{ABBREVIATIONS}

$\begin{array}{ll}\text { BA } & \text { bioavailability } \\ \text { bd } & \text { twice daily } \\ \text { BE } & \text { bioequivalence } \\ \text { tds } & \text { three times a day } \\ \text { BP } & \text { British Pharmacopoeia } \\ \text { BNF } & \text { British National Formulary } \\ \text { cGMP } & \text { current Good Manufacturing Practices } \\ \text { CRS } & \text { chemical reference standards } \\ \text { Dbc/S } & \text { double convex tablet with score market embossed one side } \\ \text { GI } & \text { gastro intestine } \\ \text { GIT } & \text { gastro intestine tract } \\ \text { EUP } & \text { European Pharmacopoeia } \\ \text { Fb/S } & \text { Flat bevelled tablet with score market embossed one side } \\ \text { FDA } & \text { Food and Drug Administration } \\ \text { HPLC } & \text { high performance liquid chromatography } \\ \text { Hr } & \text { Hour } \\ \text { Hrs } & \text { Hours } \\ \text { IP } & \text { Indian Pharmacopoeia } \\ \text { JP } & \text { Japanese Pharmacopoeia } \\ \text { min } & \text { minute } \\ \text { NLT } & \text { State Pharmaceuticals Corporation } \\ \text { SPC } & \text { Theophylline Extended Release } \\ \text { SPMC } & \text { HER }\end{array}$




\title{
Formulation of Extended Release Theophylline Tablets
}

\section{- experimental, modelling and bioequivalence studies}

Kamal Kumara Gamini Mahendranath Parakrama Bandara Herarh

\begin{abstract}
The objectives of this research project are to study the release behaviour of theophylline from the polymer matrices containing tablets, to develop an extended release theophylline formulation, to establish quality control standard specifications for the theophylline extended release tablet formulation, to scale-up the formulation for commercial manufacture, to develop a mathematical model to correlate release behaviour with the formulae, to identify the critical processes and to set manufacturing standards to ensure the reproducibility of theophylline extended release tablet formulation, to establish the bioequivalence of the formulation developed with a well prescribed preparation available in the Sri Lankan and international markets, and to market the new formulation commercially.
\end{abstract}

Extended release pharmaceutical formulations are complex, and are indicated specially in drugs having a narrow therapeutic window and a moderate half-life. The first chapter of this thesis describes studies carried out to understand the drug release behaviour of extended release formulations made from polymer matrices as applicable to theophylline, and the development of a theophylline extended release (modified or sustained release) formulation based on these studies. The selection of appropriate filler excipients was demonstrated to have a significant effect on the drug release properties of theophylline in a tablet matrices containing ammoniomethacrylate copolymer as the retarding agent. Theophylline tablets were manufactured to contain 50 to 94 percent of active ingredient, 15 to 0 percent filler excipient, and 2 to 15 percent matrices. The release rate of the drug was highest when microcrystalline cellulose was used, and slowest when calcium sulphate was used as the filler excipient, which is consistent with other reports ${ }^{79 a b}$. It was observed that when maize starch is incorporated, the tablets disintegrated with high variation in release rates from tablet to tablet. The effect of the $\mathrm{pH}$ in drug release was tested and dissolution rates in phosphate buffer media at $\mathrm{pH} 6.8$ and 7.4 were found to be much lower than at $\mathrm{pH}$ 4.5. Dissolution rates were higher in acidic media indicating that this is a factor when xvi 
calcium sulphate filler excipients are used. When no filler excipients are used dissolution rates were marginally higher or the same in near neutral $\mathrm{pH}$ media ( $\mathrm{pH} 6.8$ to 7.4 phosphate buffer) compared to the dissolution in acidic media ( $\mathrm{pH} 4.5$ phosphate buffer).

Ammoniomethacrylate Copolymer (Eudragit ${ }^{\circ}$ RS-PO) was selected as the retardant, and three strengths of theophylline extended release formulations were developed; namely $125 \mathrm{mg}$ (paediatric strength), $250 \mathrm{mg}$ and $300 \mathrm{mg}$ (adult strengths). The stability of the new formulations were tested under accelerated and ambient conditions for two years, and the shelf life of the packed product was confirmed for two years under ambient tropical conditions in Sri Lanka.

Quality control standards for theophylline extended release tablets were established, for appearance, identification, physical strength, uniformity of dosage form, drug release rate and potency, using the available standards for other similar formulae with slight modifications where appropriate.

The drug release mechanism of the tablet developed, in this study can be described as mainly dissolution rate controlling mechanism though diffusion controlled mechanism could be expected. Recognizing that both mechanisms co-exist in practice, a formula was developed that encompass both of these mechanisms. In the general dissolution model given in equation (1) diffusivity is expressed by two constants, $\alpha$ and $\boldsymbol{C}$, as well as the amount of the retarding agent $\boldsymbol{X}$, that can be used to adjust the dissolution rate.

$$
\frac{d Q}{d t}=-A \alpha D_{c}
$$

Where, $\mathrm{Q}=$ amount of the drug involved

$\mathrm{dQ} / \mathrm{dt}=$ dissolution (drug release) rate of the drug

A $=$ surface area of the tablet

$\alpha \mathrm{Dc}=$ diffusion coefficient, described by three parameters where $\alpha$ is a constant and $\mathrm{Dc}$ is a function of retarding agent ' $\mathrm{X}$ ' that expressed as percentage and a constant ' $C$ ' 
diffusivity is examined. Considering the necessity to have sufficient sensitivity to the amount of retarding agent present in the tablet the form of the exponential decay factor of the diffusivity coefficient is selected as is given in equation (2).

$$
\mathbf{D}_{\mathbf{c}}(\mathbf{X}, \mathbf{C})=\mathbf{e}^{-\mathbf{C X}}
$$

Next, the theoretical formula for a cylindrical tablet is derived and verified by applying a number of experimental data. In order to simplify the model used in the predicted dissolution, an 'equivalent radius', ErO concept is employed where the initial volume of a given tablet is represented by a spherical tablet of radius $\boldsymbol{E r} \boldsymbol{r}$. Using cylindrical tablet experiment results, it is shown that a common formula can be used to predict the dissolution rates of both cylindrical and spherical tablets. Finally, it is shown that for a given composition, common constant parameters $\boldsymbol{C}$ and $\alpha$ can be estimated, for the proposed dissolution rate required from the formula, so that it can adequately describe the dissolution rates of tablets with various amounts of retarding agent as well as the different shapes and initial dimensions.

The bio-equivalence study with twenty healthy adult volunteers was conducted with the above-developed formulation, using a reference theophylline sustained release product (Neulin SR $250 \mathrm{mg}$, manufactured by $3 \mathrm{M}$ pharmaceuticals, Australia). Serum theophylline concentrations were measured by fluorescence polarization immunoassay (FPIA). The SPMC-theophylline extended release tablet formulation developed (Manufactured by the State Pharmaceuticals Manufacturing Corporation), demonstrated that there were no significant difference between regimens with respect to bio-availability and pharmacokinetics (AUC, $C_{\max } \& \mathrm{~T}_{\max }$ ) when the test product was compared with the reference product.

The SPMC-theophylline sustained release tablet $125 \mathrm{mg}$ tablet was registered with the Drug Regulatory Authority of Sri Lanka and the first commercial order worth Rs. 50 million received from the Department of Health Supplies, Sri Lanka by winning a World Wide Open competitive tender. This amply demonstrated the commercial viability and marketability of the new product.

In conclusion all the above mentioned objectives were achieved successfully. 